\section{INTRAVENOUS MISPLACEMENT OF THE NEPHROSTOMY CATHETER FOLLOWING PERCUTANEOUS NEPHROSTOLITHOTOMY: TWO CASE REPORTS}

doi: $10.1590 / \mathrm{S} 1807-59322009000100013$

Eduardo Mazzucchi, Anuar Mitre, Artur Brito, Marco Arap, Claudio Murta and Miguel Srougi

\section{INTRODUCTION}

Percutaneous nephrostolithotomy (PCNL) was introduced by Fernström and Johansson in 1976, ${ }^{1}$ and it has remained an important approach for removing kidney stones since its inception. A nephrostomy tube is routinely positioned in the renal pelvis in order to tamponade bleeding and drain the collecting system. Although PCNL is an established procedure, major complication rates of up to $7 \%$ have been reported. ${ }^{2}$ We report two cases of an uncommon PCNL complication and details of how we managed these cases with successful outcomes.

\section{CASE REPORT}

Case 1 - A 52-year-old male who had previously undergone a right open nephrectomy of a non-functioning kidney 10 years prior underwent a left PCNL. Serum creatinine $(\mathrm{SCr})$ before surgery was $1.0 \mathrm{mg} / \mathrm{dl}$ (normal range $0.6-1.4 \mathrm{mg} / \mathrm{dl}$ ). Access to the excretory system was achieved using fascial dilators, and a safety guide wire was used during the procedure. Intense bleeding led to a sudden interruption of the procedure; a nephrostomy tube was inserted and closed in order to control bleeding within the excretory system. An antegrade nephrostogram was not performed due to intense bleeding. An arteriography was performed and showed no abnormalities. After transfusion of two units of blood, the patient remained hemodinamically stable and urine was eliminated only by means of the urethral

Division of Urology, Hospital das Clínicas, Faculdade de Medicina, Universidade de São Paulo - São Paulo/SP, Brazil.

Email: mazuchi@terra.com.br

Tel.: 55113069.8080 catheter. The nephrostomy tube remained closed.

A magnetic resonance scan performed 72 hours later showed the nephrostomy tube in the left renal vein (Figure 1). The patient was transferred to the operating room, and the nephrostomy tube was removed under general anesthesia with the surgical team on standby ready to intervene. No bleeding occurred after removal of the catheter. The patient was discharged with a SCr level of $1.4 \mathrm{mg} / \mathrm{dl}$.

Case 2 - A 35-year-old female underwent a second PCNL for a staghorn stone in the left kidney. She had previously lost her right kidney due to kidney stones. The SCr level before surgery was $3.0 \mathrm{mg} / \mathrm{dl}$. A PCNL was performed; access to the excretory system was gained using coaxial dilators, and a safety guide wire was used during the procedure. An ultrasonic energy source was used to fragment

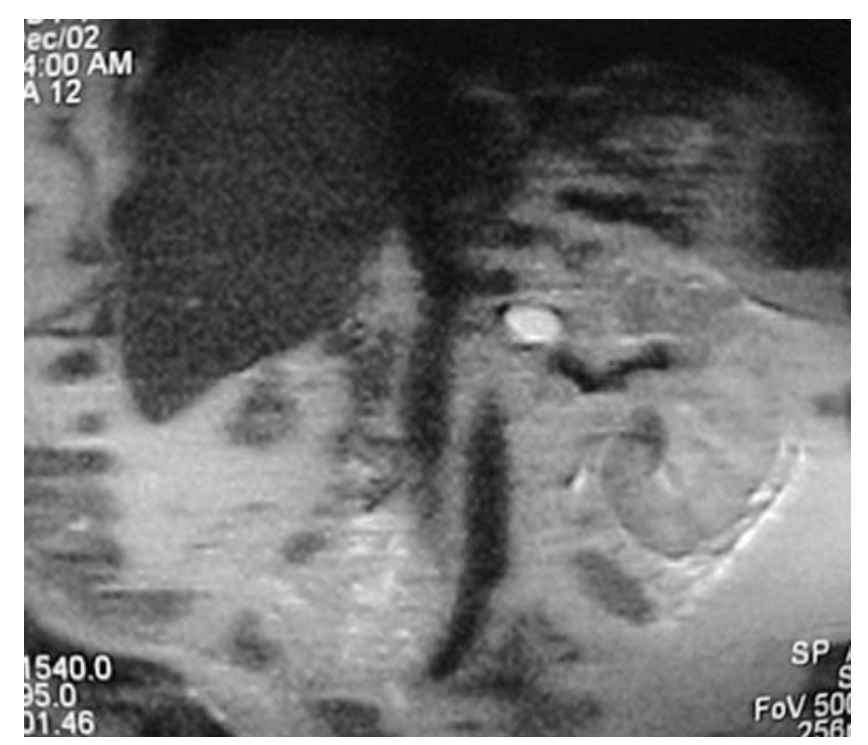

Figure 1 - MRI demonstrating the Foley catheter balloon inside the left renal vein 


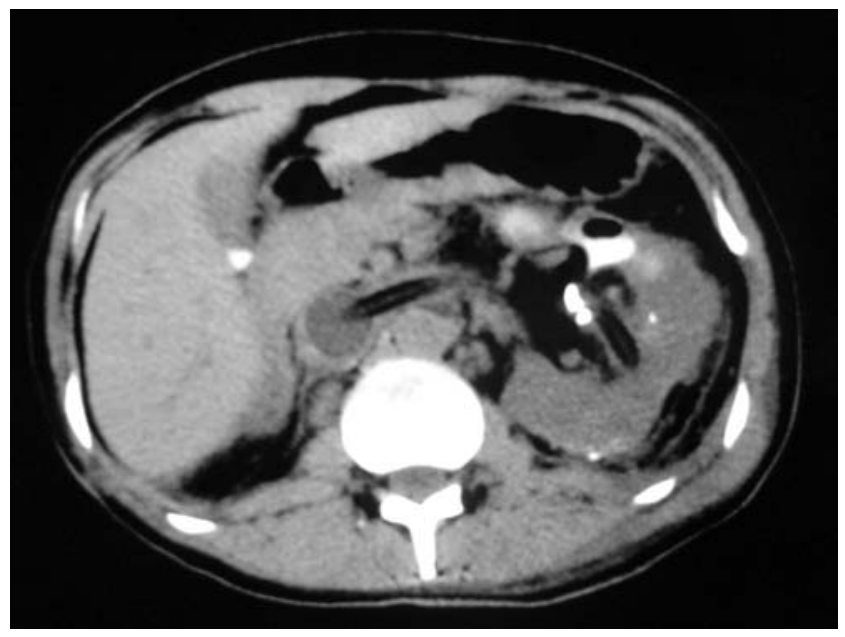

Figure 2 - CT showing the Foley catheter nephrostomy balloon inside the inferior vena cava

the stone. Severe venous bleeding was noted during the fragmentation process. The procedure was interrupted; a nephrostomy tube was inserted and maintained closed. The nephrostomy was reopened on the second postoperative day, and intense bleeding was observed through the catheter, which was immediately closed. An antegrade nephrostogram was performed and showed the presence of iodinated contrast inside the venous system. A computed tomography scan showed that the nephrostomy catheter was lodged inside the inferior vena cava (Figure 2). The patient was taken to the operating room, and the nephrostomy tube was repositioned in the collecting system under fluoroscopy control with the surgical team on standby ready to intervene. The nephrostomy tube was removed 48 hours later. The patient was discharged three days later with a SCr level of $3.5 \mathrm{mg} / \mathrm{dl}$.

\section{DISCUSSION}

Hemorrhage is the most significant complication of PCNL, and transfusion can be necessary in up to $10 \%$ of procedures. ${ }^{2}$ Other complications include sepsis, adjacent organ perforation (such as liver, spleen, and bowel), failed renal access, perforation of the excretory system, pneumothorax, and pleural effusion. ${ }^{2}$ Placing a nephrostomy tube in the collecting system following PCNL is a routine practice, and, in addition to its other advantages, it is an effective method for stopping venous bleeding. ${ }^{3}$ Occasionally, the catheter can pierce the renal parenchyma and migrate into the renal vein and even to the vena cava. ${ }^{3}$

In the first case, the nephrostomy tube was removed, and it was relocated under fluoroscopic guidance in the second. In both cases, the patients were placed under general anesthesia, and while the surgical teams were ready to perform emergency open surgery in the event of uncontrolled bleeding, this was not necessary.

This study is the second report in the literature regarding misplacement of a nephrostomy tube into the vascular system and is the first report of such a complication following PCNL. ${ }^{4} \mathrm{~A}$ lesion in a large renal vein branch caused by the instruments used during percutaneous surgery was the most likely cause of the observed bleeding. Furthermore, the proximity of the Amplatz sheath to the injured vein could have inadvertently directed the nephrostomy tube inside the venous system.

Although a Doppler ultrasound was not performed after the nephrostomy tubes were removed, we conclude that no renal or vena cava thrombosis occurred, as these kidneys were single organs and renal function was maintained after the procedures in both patients. Thrombotic phenomena were probably not observed due to the high blood flow and low venous pressure inside these veins.

Antegrade pyelographies were not performed in either procedure due to the bleeding, and this decision was likely a mistake. Antegrade pyelography at the end of a percutaneous procedure in order to check the exact positioning of the nephrostomy tube should be mandatory, even in cases of severe bleeding, and must be done routinely. In cases where misplacement of the tube is detected, depending on the postoperative time elapsed, relocation of the nephrostomy tube under fluoroscopy is strongly recommended, and the surgical team must stand ready to operate in case an open emergency procedure is required.

\section{REFERENCES}

1. Ferström I, Johansson B: Percutaneous pyelolithotomy: A new extraction technique. Scand J Urol Nephrol. 1976; 10:257-60.

2. Lingeman JE, Matlaga BR, Evan AP.: Surgical management of upper urinary tract calculi. In: Wein AJ et al (editors). Campbell-Walsh Urology, $9^{\text {th }}$ edition.Philadelphia: Saunders; 2007. p.1500
3. Winfield HN, Weyman P, Clayman RV. Percutaneous nephrostolithotomy: Complications of premature nephrostomy tube removal. J Urol. 1986; 136:77-9.

4. Dias-Filho AC, Coaracy GAV, Borges W. Right atrial migration of nephrostomy catheter. Int Braz J Urol. 2005; 31:470-1. 